\title{
An amphiphilic, heterografted polythiophene copolymer containing biocompatible/biodegradable side chains for use as (electro)active surface in biomedical applications
}

\author{
Brenda G. Molina, ${ }^{a, b, \$}$, Luminita Cianga, ${ }^{c, \$}$ Anca-Dana Bendrea, ${ }^{c}$ Ioan Cianga, ${ }^{c, *}$ Carlos Alemán ${ }^{a, b, d}$ and Elaine Armelin ${ }^{a, b, *}$ \\ a) Departament d'Enginyeria Química, EEBE, Universitat Politècnica de Catalunya, C/ Eduard Maristany, 10-14, Ed. I.2, 08019, Barcelona, Spain. \\ b) Barcelona Research Center for Multiscale Science and Engineering, Universitat Politècnica de Catalunya, C/ Eduard Maristany, 10-14, Ed. I.S, 08019, \\ Barcelona, Spain. \\ c) "Petru Poni" Institute of Macromolecular Chemistry, 41A, Grigore -Ghica Voda Alley, 700487, lasi, Romania. \\ d) Institute for Bioengineering of Catalonia (IBEC), The Barcelona Institute of Science and Technology, Baldiri Reixac 10-12, 08028 Barcelona Spain \\ *Corresponding authors: ioanc@icmpp.ro and elaine.armelin@upc.edu \\ Electronic Supplementary Information (ESI) available
}

\begin{abstract}
Given that the copolymers of complex topology and composition are at the forefront of multifunctional materials research, this work reports about an amphiphilic random, heterografted copolymer of $(A-g-B)_{m}-r a n-(A-g-C)_{n}$ type, which was designed to work as an efficient and biocompatible electronic interface. The copolymer (henceforth denoted as PTh- $g$-(PEG-r-PCL) for simplification) was synthesized in hierarchical fashion, having $\pi$-conjugated polythiophene (PTh) as main chain and polar units, polyethylene glycol (PEG) and oligo- $\varepsilon$-caprolactone as side chains. The properties of the new copolymer, in solution and in solid state, were evaluated. The applied investigations showed that, due to its amphiphilic character and incompatibility of the side chains, PTh- $g$-(PEG- $r$-PCL) experiences microphase separation in solution and film states. By electronic microscopy techniques were evidenced two types of supramolecular structures: (a) porous spherical particles and (b) rod-like structures. When deposited on carbon electrodes, the copolymer presented a good electroactivity and electrostability. Copolymer's biocompatibility studies, performed by using Cos-1 and Vero cell lines, demonstrated an excellent adhesion when comparing with bare steel electrode while a slight decrease of proliferation was registered, more pronounced for Vero cells, in spite of cells normal growth and morphology. Thanks to its excellent capability for electrochemically interfacing with aqueous electrolytes, the voltammetric oxidation of NADH coenzyme at PTh- $g$-(PEG- $r$ $\mathrm{PCL}$ ) film-modified carbon electrode revealed that it can be used as selective biosensor of this biomolecule, as well.
\end{abstract}

\section{Introduction}

Amphiphilic block copolymers (ABCPs) are micro-segregated systems capable of self-assembly (SA) to give rise to nanostructures (e.g. micelles, vesicles, core-shell particles), whose characteristics are regulated by the length, chemical nature, and mutual arrangement of their hydrophilic and hydrophobic constituent blocks. ${ }^{1}$ Another important aspect of today material science is connected to nanostructured materials design. In this context, nanostructuration, by using SA strategy, has increasingly emerged as an elegant "bottom-up" approach for the design and the fabrication of reproducible nanoscale structures, both in solution and in solid states. ${ }^{2}$ In the last years, these systems have gained increasing attention because of their outstanding applications in drug delivery systems, $^{3-5}$ sensors, ${ }^{6,7}$ imaging probes, ${ }^{8,9}$ and catalysts, ${ }^{10,11}$ among others, as for example, in anticancer therapy. ${ }^{12}$

Furthermore, some graft copolymers that incorporates conducting polymers (CPs), where the $\pi$-conjugated chains are connected with flexible, hydrophilic or hydrophobic side chains, are another interesting class with a particular property, sensitivity to external stimuli (electrical or chemical), caused by their conjugated structure. ${ }^{13-16}$ Among CPs, polythiophene (PTh) and its derivatives are particularly important due to their high stability, controllable electrochemical behaviour, and ease chemical and structural modification. ${ }^{17,18}$ On the other hand, biodegradable and biocompatible graft copolymers based on polycaprolactone $(\mathrm{PCL}$ ) and polyethylene glycol (PEG) units are reported to be an important class in amphiphilic macromolecules for drug delivery ${ }^{19-23}$ and bioimaging applications. ${ }^{24}$ Moreover, the building blocks, PEG and PCL, are FDA approved polymers. ${ }^{25}$ In aqueous media, linear PCL- $b$-PEG $A B C P s$ form $S A$ nanostructures with $P C L$ as the hydrophobic core and $P E G$ as the hydrophilic corona-like structure around the core. ${ }^{26} \mathrm{PCL}$ is biodegradable and PEG is usually removed from the body by bioelimination.

In recent years, we have developed several amphiphilic and biocompatible PTh-based grafted copolymers using the "grafting-through" approach (also named macromonomer method). ${ }^{27-29}$ For this purpose, chemically synthesized thiophene (Th)-based macromonomers bearing a PEG or PCL side chains with low molecular weight have been polymerized, or copolymerized to space out the biocompatible side blocks, via electrochemical copolymerization. ${ }^{14,27-29}$ Moreover, the applicability of these materials as bioactive cellular matrices and electroactive bioadhesive surfaces for biomedical and biotechnological applications, respectively, was demonstrated. ${ }^{14,27-29}$ Furthermore, the PTh-based graft copolymers bearing low molecular weight PCL chains showed a sensitive and selective capability for dopamine (DA) detection, proving that such hybrid materials are potential candidates for the fabrication of implantable DA sensors. ${ }^{28}$ 
Nowadays, the development of biosensing devices for the detection of $\beta$-nicotinamide adenine dinucleotide (NADH) has gained interest because of its participation as enzymatic cofactor in more than 300 dehydrogenases and as electron carrier in cell processes associated to energy production. ${ }^{30,31}$ Among the NADH detection methods, the electrochemical ones are highlighted because of their advantages: easy handling, small sampling volume, less-interferences, user friendly, easily applicable for field analysis and less cost. ${ }^{32}$ However, the utilization of conventional Pt electrodes to detect the oxidation of NADH into NAD+, which is achieved by removing one electron from the nitrogen atom of the nicotinamide ring, requires high potential $(+1.0 \mathrm{~V}) .{ }^{30}$ This represents a serious inconvenient for biomedical applications and, therefore, the design and fabrication of alternative electrodes able to use lower potentials is required.

In the context of these findings, the current paper describes the synthesis, structural characterization and properties investigations of a new heterografted rod-coil statistical copolymer, having $\pi$ conjugated polythiophene (PTh) as main chain and polar, thermodynamically incompatible, polyethylene glycol $\left(\mathrm{PEG}_{2000}\right)$ and oligo- $\varepsilon$-caprolactone $(\mathrm{OCL})$ as side chains. It is worth noting that, such copolymer, hereafter denoted PTh- $g$-(PEG-r-PCL), are constituted by independent oligo- $\varepsilon$-caprolactone and PEG side chains attached to the PTh backbone rather than connected between them, as in conventional PCL-PEG building block copolymers. Thus, synergistic combination of PCL, PEG and PTh units for obtaining improved properties of multifunctional materials, represents a great synthesis sophistication with respect to PCL- $b$-PEG ABCPs and to the PThbased grafted copolymers having only one type of side chains.

\section{Experimental section}

\subsection{Materials}

Poly(ethylene glycol) methyl ether $\mathrm{M}_{\mathrm{n}}=2000 \mathrm{~g} / \mathrm{mol}$ (hereafter denoted $\mathrm{PEG}_{2000}$ ), thiophene-3-carboxylic acid (98\%), N,N'dicyclohexylcarbodiimide (DCCl, 99\%), 4-dimethylamino pyridine (DMAP, $\geq 98 \%$ ), 3-thiophene-methanol (Th-MeOH, $98 \%), \varepsilon$-caprolactone ( $\varepsilon-\mathrm{CL} ; 97 \%)$, stannous octoate ( $\mathrm{Sn}(\mathrm{Oct})_{2}$, 92.5-100\%), anhydrous $\mathrm{FeCl}_{3}(\geq 98 \%)$ and hydrazine monohydrate (98\%) were used as received. Solvents were purified and dried by usual methods. The solvent used for the characterization of the copolymer was acetone ( $\geq 99.9 \%$ SigmaAldrich). For electrochemical trials, a Dulbecco's phosphate buffered saline solution (PBS) $0.1 \mathrm{M}$ with $\mathrm{pH} 7.4$, without calcium chloride and magnesium chloride, was used, meanwhile detection assays were carried out with NADH, reduced disodium salt hydrate $(\geq 97 \%)$ and ascorbic acid (AA; Lconfiguration, crystalline) from Sigma-Aldrich Co.

\subsection{Synthesis of macromonomers and PTh-g-(PEG-r-PCL) copolymer}

2.2.1. Synthesis of PEG-based thiophene macromonomer (ThPEG)

First, $2 \mathrm{~g}(0.001 \mathrm{~mol})$ of $\mathrm{PEG}_{2000}$ and $0.19 \mathrm{~g}$ (0.0015 mol) of thiophene3-carboxylic acid were placed into a three-neck round-bottom flask equipped with a dropping funnel, under nitrogen. Then, $20 \mathrm{~mL}$ of $\mathrm{CH}_{2} \mathrm{Cl}_{2}$ and $0.0171 \mathrm{~g}$ of DMAP $0.14 \mathrm{mmol}$ ) were added to the flask, whereas $0.304 \mathrm{~g}(0.00147 \mathrm{~mol})$ of $\mathrm{DCCl}$ in $1 \mathrm{~mL} \mathrm{CH}_{2} \mathrm{Cl}_{2}$ were placed in the dropping funnel and added to the reaction flask in about $5 \mathrm{~min}$. The mixture was stirred at room temperature for three days. The resulting dicyclohexyl urea was removed by filtration and the resulting solution was precipitated in cold diethyl ether to remove the catalyst and the unreacted reagents. After filtration and drying, the macromonomer was obtained as a white solid. The molecular weight of the macromonomer, as determined by GPC measurements $\left(M_{n}=2486 \mathrm{Da}\right)$, was slightly higher than the calculated one. This was attributed to the polarity difference between the PEG chains and the polystyrene used as standard. The index of polydispersity (IPD) was 1.04 .

${ }^{1} \mathrm{HNMR}$ (acetone- $\mathrm{d}_{6}, \delta$ in ppm): 8.27- 7.52ppm ( $\mathrm{CH}$ protons of the thiophene ring), 4.40ppm ( $\left.\mathrm{CO}-\mathrm{OCH}_{2}\right), 3.81-3.57 \mathrm{ppm}\left(\mathrm{CH}_{2} \mathrm{O}\right.$ from $\mathrm{PEG})$, and $3.30 \mathrm{ppm}\left(\mathrm{OCH}_{3}\right)$.

IR $(\mathrm{KBr}), \mathrm{cm}^{-1}: 3108 \mathrm{~cm}^{-1}(\beta(\mathrm{C}-\mathrm{H})$ stretching vibration and $\alpha(\mathrm{C}-\mathrm{H})$ stretching vibration of the thiophene ring), $2889 \mathrm{~cm}^{-1}\left(\mathrm{v}_{\text {as }} \mathrm{CH}_{2}\right.$ from PEG), $2740 \mathrm{~cm}^{-1}\left(v_{\mathrm{s}} \mathrm{CH}_{2}\right.$ from PEG), $1716 \mathrm{~cm}^{-1}(v \mathrm{C}=0$ of the ester group between thienyl moiety and PEG), $1632 \mathrm{~cm}^{-1}$ and $1524 \mathrm{~cm}^{-1}$ (antisymmetric and symmetric stretching vibrations of the thienyl ring), $1467 \mathrm{~cm}^{-1}\left(\delta \mathrm{CH}_{2}\right.$ from $\left.\mathrm{PEG}\right), 1360 \mathrm{~cm}^{-1}, 1343 \mathrm{~cm}^{-1}\left(\mathrm{CH}_{2}\right.$ wagging from PEG), $1280 \mathrm{~cm}^{-1}\left(\mathrm{CH}_{2}\right.$ twisting from PEG), $1242 \mathrm{~cm}^{-1}\left(\mathrm{CH}_{2}\right.$ twisting and CO-C stretching from $P E G), 1149 \mathrm{~cm}^{-1}$ ( $v C O$ from $\left.P E G\right)$, $1114 \mathrm{~cm}^{-1}$ (CO-C stretching from $\left.\mathrm{PEG}\right), 1060 \mathrm{~cm}^{-1}\left(\mathrm{CH}_{2}\right.$ rocking and $\mathrm{C}$ $\mathrm{O}-\mathrm{C}$ stretching from $\mathrm{PEG}), 963 \mathrm{~cm}^{-1}\left(\mathrm{CH}_{2}\right.$ rocking from $\left.\mathrm{PEG}\right), 842 \mathrm{~cm}$ ${ }^{1}(\mathrm{r}(\mathrm{CH} 2)+v(\mathrm{C}-\mathrm{O}-\mathrm{C})$ from $\mathrm{PEG}), 751 \mathrm{~cm}^{-1}(\mathrm{C}-\mathrm{S}), 530(v$ thienyl ring deformation).

\subsubsection{Synthesis of PCL-based thiophene macromonomers (Th-PCL)}

Thiophene-ended oligo- $\varepsilon$-caprolactone (Th-PCL) macromonomer was synthesized using a previously reported procedure, ${ }^{28}$ with the only difference of the molar ratio between initiator and monomer $([\mathrm{I}] /[\mathrm{M}])$, which has been changed from $1 / 20$, in previous work, to $1 / 18$ in this work. The molecular weight of this macromonomer, as estimated from the ${ }^{1} \mathrm{H}-\mathrm{NMR}$ data $\left(\mathrm{M}_{\mathrm{n}} \mathrm{H}-\mathrm{NMR}\right)$ was 2283 Da. Besides, GPC measurements led to $M_{n}$ and PD values of $3070 \mathrm{Da}$ and 1.47, respectively.

${ }^{1} \mathrm{HNMR}\left(\mathrm{CDCl}_{3}, \delta\right.$ in ppm): 7.33ppm, 7.09ppm ( $\mathrm{CH}$ protons of the thiophene ring), $5.14 \mathrm{ppm}\left(\mathrm{Th}-\mathrm{CH}_{2}\right), 4.10-4.06 \mathrm{ppm}\left(\mathrm{CH}_{2}-\mathrm{O}\right), 3.66 \mathrm{ppm}$ $\left(\mathrm{CH}_{2}-\mathrm{OH}\right)$, 2.37-3.31 ppm ( $\left.\mathrm{CH}_{2} \mathrm{COO}\right), 1.80-1.52 \mathrm{ppm}\left(-\mathrm{CO}-\mathrm{CH}_{2}-\mathrm{CH}_{2}-\right.$ $\mathrm{CH}_{2}-\mathrm{CH}_{2}-\mathrm{CH}_{2}-\mathrm{O}-$ ), 1.44-1.36 (- $\mathrm{CO}-\mathrm{CH}_{2}-\mathrm{CH}_{2}-\mathrm{CH}_{2}-\mathrm{CH}_{2}-\mathrm{CH}_{2}-\mathrm{O}-$ ).

IR $(\mathrm{KBr}), \mathrm{cm}^{-1}: 3108 \mathrm{~cm}^{-1}(\beta(\mathrm{C}-\mathrm{H})$ stretching vibration and $\alpha(\mathrm{C}-\mathrm{H})$ stretching vibration of the thiophene ring), $2945 \mathrm{~cm}^{-1}\left(\left(\mathrm{v}_{\mathrm{as}} \mathrm{CH}_{2}\right.\right.$ from $\mathrm{OCL}), 1725 \mathrm{~cm}^{-1}((\mathrm{vC}=\mathrm{O}$ of the ester group between thienyl moiety and PCL), $1560 \mathrm{~cm}^{-1}, 1472 \mathrm{~cm}^{-1}$ and $1419 \mathrm{~cm}^{-1}\left(v_{\text {sym }}(\mathrm{C}-\mathrm{H})\right.$ and $v_{\text {asym }}$ (C-H )of the thienyl ring), $1295 \mathrm{~cm}^{-1}(v \mathrm{C}-\mathrm{O}$ and $v \mathrm{C}-\mathrm{C})$ and $1192 \mathrm{~cm}^{-1}$ $\left(v_{\text {sym }}(\mathrm{OC}-\mathrm{O})\right.$ oligocaprolactone crystallization sensitive bands), 1047 $\mathrm{cm}^{-1} \quad\left(\left(v_{\mathrm{as}} \mathrm{C}-\mathrm{O}\right.\right.$ from $\left.\mathrm{OCL}\right), 706 \mathrm{~cm}^{-1}(\mathrm{C}-\mathrm{S}), 581 \mathrm{~cm}^{-1}(\nu$ ring deformation) and $450 \mathrm{~cm}^{-1}(\mathrm{C}-\mathrm{S}-\mathrm{C})$.

\subsubsection{Synthesis of PTh- $g$-(PEG-r-PCL) copolymer by chemical oxidative polymerization}

A $25 \mathrm{~mL}$ round bottom flask equipped with magnetic stirrer and a lateral neck with a dropping funnel was used. The system was 
vacuumed and back-filled with dry nitrogen for several times. Then $2.1 \mathrm{~mL} \mathrm{CHCl}_{3}, 0.360 \mathrm{~g}$ (0.17 mmol) Th-PEG and $0.392 \mathrm{~g}$ (0.17 mmol) Th-OCL were introduced under inert atmosphere. After the complete dissolution of the reactants, the mixture was cooled down at $0^{\circ} \mathrm{C}$ and $0.211 \mathrm{~g}(1.3 \mathrm{mmol})$ of anhydrous $\mathrm{FeCl}_{3}$ in $3.5 \mathrm{~mL} \mathrm{CHCl} 3$ was added dropwise during $25 \mathrm{~min}$. The reaction mixture was stirred at room temperature for 4 days. After that time, the copolymer was separated by precipitation in diethylether, filtered and dried at room temperature under vacuum. Further purification was achieved by silicagel column chromatography, using $\mathrm{CH}_{2} \mathrm{Cl}_{2}$ as eluent. The resulted solution was concentrated in a rotaevaporator and subsequently reprecipitated in diethyl ether. The obtained copolymer was dedoped by stirring its solution in $\mathrm{CH}_{2} \mathrm{Cl}_{2}$ with hydrazine hydrate for 30 minutes. After washing of organic layers twice with water, the dedoped copolymer was obtained by precipitation with diethyl ether.

The obtained doped PTh- $g$-(PEG-r-PCL) copolymer was dedoped by stirring its solution in $\mathrm{CH}_{2} \mathrm{Cl}_{2}$ with hydrazine hydrate for 30 minutes. After washing of organic layers twice with water, the dedoped copolymer was obtained by precipitation with diethyl ether. The synthetic route is summarized in Scheme 1.
(A)<smiles>O=C(O)c1ccsc1</smiles>

Thiophene-3-carboxylic acid<smiles>COCC(C)(C)OC</smiles>

PEG $_{2000}$

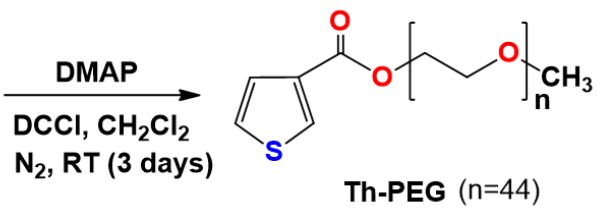

Th-PEG $(n=44)$

(B)<smiles>OCc1ccsc1</smiles>

3-Thiophenemethanol<smiles>O=C1CCCCCO1</smiles>

$\varepsilon-\mathrm{CL}$<smiles>CC(=O)CCCCCOCc1ccsc1</smiles>

Th-OCL $(m=19)$

(C)

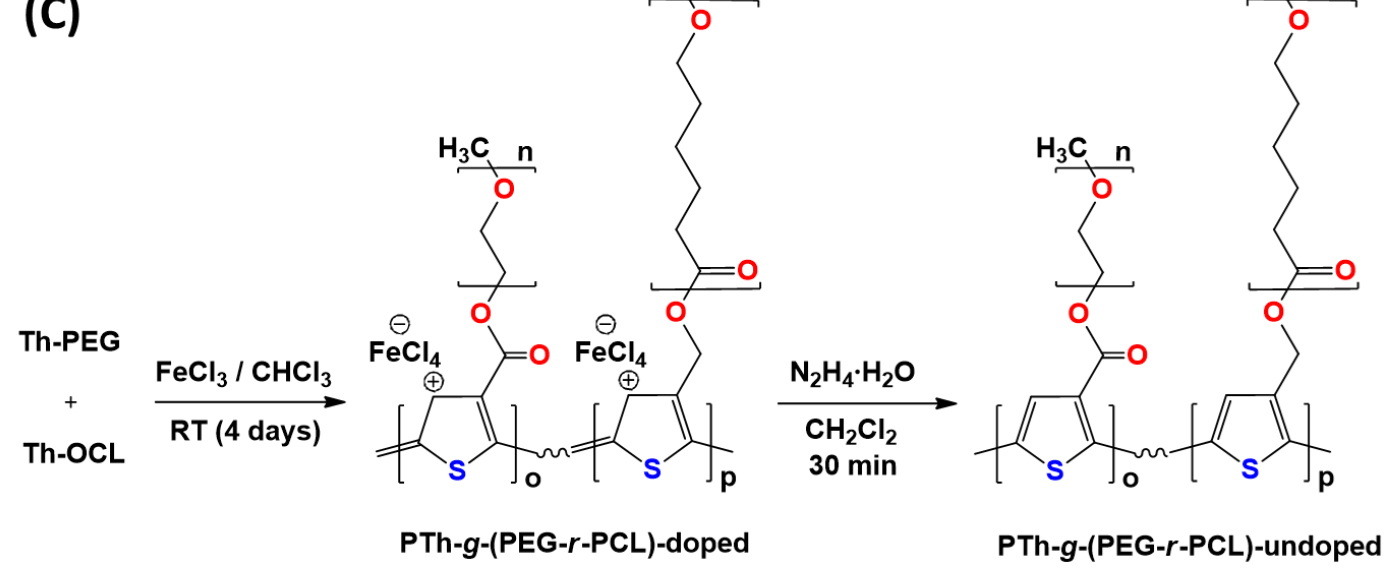

Scheme 1. Synthesis of PTh-g-(PEG-r-PCL) copolymer: (A) Esterification reaction of thiophene derivative and PEG 2000 ; (B) Esterification reaction of thiophene derivative and oligo- $\varepsilon$-caprolactone; and $(C)$ oxidative polymerization of macromonomers from $(A)$ and $(B)$ and dedoping reaction with hydrazine.

\subsection{Polymer characterization}

A detailed description of the methods followed for the macromonomers and copolymer characterization is included in the supporting information (ESI). The precursors and final product were characterized by NMR and FTIR spectroscopies, and the molecular weight was approached with gel permeation chromatography (GPC). The copolymer was also investigated in acetone solution by dynamic light scattering (DLS) and for photophysical properties, by UV-vis and fluorescence analyses. The microparticles obtained from PTh-g(PEG-r-PCL) copolymer were evaluated by scanning electron microscopy (SEM), transmission electron microscopy (TEM) and dynamic light scattering (DLS); whereas the electrochemical characterization was performed with cyclic voltammetry (CV), differential pulse voltammetry (DPV) and chronoamperometry (CA). Cos-1 and Vero monkey kidney epithelial cells were employed for the biocompatibility approach in vitro. 


\section{Results and discussion}

\subsection{Molecular design and structural characterization of PTh-g-} (PEG-r-PCL) copolymer

The new amphiphilic heterografted copolymer was synthesized by combining the so-called "macromonomer" or "grafting through" technique, $28,29,33-35$ via oxidative polycondensation reaction of an equimolecular mixture of two thiophene-ended macromonomers (Scheme 1), a classical method for CPs chemical synthesis. The hydrophilic macromonomer, Th-PEG, was synthesized by chain-end functionalization method, through Steglich esterification of hydroxyl group of $\mathrm{PEG}_{2000}$ (Scheme 1A), being the first time it has been reported. The Th-PCL monomer, of hydrophobic nature, was obtained as previously reported method, ${ }^{28}$ using thiophene methanol for ring-opening polymerization (ROP) of oligo- $\varepsilon-\mathrm{CL}$, (Scheme 1B). We should mention that the resulting compound is oligomeric in its nature, despite we preferred use the acronym of $\mathrm{PCL}$ in the whole work, instead of OCL. For both expected structures' confirmation, spectroscopic methods ( ${ }^{1} \mathrm{H}-\mathrm{NMR}$ and FTIR) were applied beside GPC, which give the information about apparent molecular weight as well as the index of polydispersity (IPD, Table $\mathrm{S} 1)$. It has to be mentioned that polymerization degree $(P D=19)$ of $\mathrm{OCL}$ in thiophene units and its molecular weight $\left(2283 \mathrm{~g} \cdot \mathrm{mol}^{-1}\right)$ were assessed by ${ }^{1} \mathrm{H}-\mathrm{NMR}$ measurement (Table $\mathrm{S} 1$ ) and the obtained values were further taken in account for copolymer synthesis recipe calculation, according to previous studies. ${ }^{28,36}{ }^{1} \mathrm{H}-\mathrm{NMR}$ and FTIR analyses from starting materials have been included in Figures S1-S2. As PEG and PCL monomers are crystallisable substances, it is worthy to notice the presence of such absorption bands in the FTIR spectra (Figures S2a-b). They can be summarized as follow: (i) - triplet maxima of C-O-C stretching vibrations of PEG at 1148, 1114 and 1060 $\mathrm{cm}^{-1}$, besides $1360 \mathrm{~cm}^{-1}$ and $1280 \mathrm{~cm}^{-1}$ (PEG 7/2 helix), while 10/3 helical conformation is proven by absorptions at 1242 and $963 \mathrm{~cm}$ 1;29,36 for Th-PEG (Figure S2a); (ii) - crystallization-sensitive bands at $1726 \mathrm{~cm}^{-1}$ ( $\mathrm{vC}=\mathrm{O}$ ester), at $1294 \mathrm{~cm}^{-1}$ ( $\mathrm{v} \mathrm{C}-\mathrm{O}$ and $\left.\mathrm{v} \mathrm{C}-\mathrm{C}\right)$, and at 1189 $\mathrm{cm}^{-1}$ ( $v$ OC-O) for Th-OCL (Figure S2b).

For the copolymer preparation, although the thiophene ring reactivities of Th-PEG and Th-PCL are naturally different, equal molar amount of such co-macromonomers in the feed was used. After the work-up of the resulted reaction mixture, including the de-doping stage with hydrazine, only water-insoluble part was kept (Scheme 1C). Then, the copolymer was purified until the GPC measurement showed a unimodal curve (Figure S3c).

The structural characterization of the statistically grafted copolymer PTh-g-(PEG-r-PCL) was elucidated by NMR (acetone- $d_{6}$ ). Thus, in Figure $1 \mathrm{a}$, all the observable signals in the ${ }^{1} \mathrm{H}-\mathrm{NMR}$ spectrum were assigned to each type of protons belonging to PEG (c, c', c", d) and $\operatorname{PCL}(\mathbf{f}, \mathbf{g}, \mathbf{i}, \mathbf{j})$ side chains, as well as those characteristic to the polythiophene conjugated main chain, $(\mathbf{a}, \mathbf{b})$, as a broadened peak placed in the range $6.9 \mathrm{ppm}-8.12 \mathrm{ppm}$. Moreover, the signals attributable to protons of methylene group (e), in the PCLsubstituted structural units, can be seen in the range of $5.05 \mathrm{ppm}$ $5.41 \mathrm{ppm}$. In general, for the 3-substituted polythiophenes the shape and positions of the three peaks $(\mathbf{a}, \mathbf{b}$, and $\mathbf{e})$ can give information about the coupling of the monomers and about the regioregularity of the obtained polymer. Such shifts of each non-symmetric structural unit observed in the ${ }^{1} \mathrm{H}-\mathrm{NMR}$ spectrum of PTh-g-(PEG-r-PCL) give one idea about the polymer regioregularity: head-tail $(\mathrm{H}-\mathrm{T})$, head-head $(\mathrm{H}-\mathrm{H})$ and tail- tail ( $\mathrm{T}$ $\mathrm{T})$. Moreover, as $\alpha(1)$-methylene protons and even $\beta(2)$ methylene protons in poly-3-alkylthiophenes, due to the difference in configuration, present split peaks associated to $\mathrm{H}$ $\mathrm{H}$ and $\mathrm{H}-\mathrm{T}$ dyads, from the intensities of these characteristic peaks the named dyads ratio can be evaluated. ${ }^{37}$

Interestingly, in the spectrum of PTh- $g$-(PEG- $r$-PCL), in the range $5.05 \mathrm{ppm}-5.41 \mathrm{ppm}$, two separated peaks are present at $5.05-5.01 \mathrm{ppm}$ and $5.39-5.41 \mathrm{ppm}$, that could be attributed to both types of dyads, commented above, in the structural units of the new copolymer. However, due to the statistical distribution of the side chains, as well as the presence of other possibilities for PTh main chain ends, it makes complicate the calculation of such $\mathrm{H}-\mathrm{H} / \mathrm{H}-\mathrm{T}$ dyads ratio in the range of 5.05-5.41 $\mathrm{ppm}$. Therefore, we used the information given by the ${ }^{1} \mathrm{H}-\mathrm{NMR}$ technique for its evaluation. To this aim, the integral values of the peaks j, c, c', c' and $\mathbf{d}$ (Figure 1a) were combined in order to obtain the values $\mathbf{o}(0.4)$ and $\mathbf{p}(0.6)$ (code of structural units showed in the Scheme $1 C)$, determining that PTh-g-(PEG-r-PCL) contain $40 \%$ PEG side chains and $60 \%$ PCL side chains. Considering this composition of copolymer, its hydrophiliclipophilic balance (HLB) was calculated as previously reported ${ }^{38}$ and a value of 0.36 was obtained, which characterizes an amphiphilic, non-water-self dispersible material.

New interesting information was also obtained by analysing ${ }^{13} \mathrm{C}$ NMR spectrum from Figure $1 \mathrm{~b}$. Because these aspects are relevant for the spectrum interpretation, it is worthy to mention that acetone, used for the spectrum registration, is better solvent for PEG units as well as for oligo- $\varepsilon-\mathrm{CL}$ (if the Hildebrand solubility, $\delta$, and solventpolymer interaction, $\chi$, parameters are taken in account, Table S2), than for PTh units. Thus, as expected, the signals originating from PEG structural units appeared at $71.28 \mathrm{ppm}$ (carbon atoms denoted 4 in Figure 1b), while those belonging to $P C L,(10-13)$, are concentrated in the range of $24.2 \mathrm{ppm}-34,71 \mathrm{ppm}$, excepting carbon atom 14, placed in the neighbourhood of oxygen atom from ester; it can be seen at $64.4 \mathrm{ppm}$. The carbonyl groups of ester linkages, belonging to Th-PEG and PCL side chains, appeared at 173.58 ppm, as well.

Interestingly, some of the signals attributable to the first and the last structural units of PEG (count starting from the thiophene ring) and to the structural unit of $\mathrm{PCL}$, placed at its chain end, appeared separately in the spectrum of Figure $1 \mathrm{~b}$. Nevertheless, what is intriguing is the fact that from eight carbon atoms belonging to the two types of thiophene rings in the main chain of copolymer, only two of them are hardly discernible. Thus, for a more accurate assignment of the amphiphilic side chains present in PTh-g-(PEG-r-PCL) copolymer, a study with DEPT $135{ }^{13} \mathrm{C}-\mathrm{NMR}$ registration was performed (Figure 1c). This technique allowed to discriminate among the peaks from methylene in PEG and PCL side chains, as well as to assign the peaks of thiophene rings. As for example, the carbon atoms 17 and $\mathbf{1 8}$ showed in the Figure 1c, correspond to the hydrogen atoms connected to the $\beta$-position of thiophene heterocycle, that was not clearly discerned in the ${ }^{13} \mathrm{C}-\mathrm{NMR}$ (Figure $1 \mathrm{~b}$ ). The explanation for the lack of $\mathrm{C}$ atoms in 
normal ${ }^{13} \mathrm{C}-\mathrm{NMR}$ can be explained based on the combination of two factors: (i)-the grafted side chains, both of them in extended configuration in a good solvent like acetone, restrict the mobility of the rigid, hydrophobic polythiophene main chain for which acetone is a bad solvent, leading to small peaks broadening in the ${ }^{13} \mathrm{C}-\mathrm{NMR}$, making them hard to discern; and (ii)- the side chains at high grafting density can shield the polythiophene main chain carbon atoms resonance.

The FTIR spectrum of PTh- $g$-(PEG-r-PCL) (Figure 2) shows the typical signals originating from aliphatic $\mathrm{CH}_{2}$ and $\mathrm{CH}_{3}$ in the range of 2992-2818 $\mathrm{cm}^{-1}$ besides a shallow absorption centered approximately at $3066 \mathrm{~cm}^{-1}$ corresponding stretching vibration of thiophene rings in the main chain ( $\beta \mathrm{C}-\mathrm{H}$ aromatic). It is remarkable that relatively broad absorptions appeared. They are placed in the range of $3137-3072 \mathrm{~cm}^{-1}$, for Th-PEG, and 3132-3080 $\mathrm{cm}^{-1}$ for Th-PCL (Figure S2a-b); and they are attributable to both aromatic $\alpha(\mathrm{CH})$ and $\beta(\mathrm{CH})$ stretching vibrations of thiophene rings. Those absorption bands at 752 $\mathrm{cm}^{-1}$ and $782 \mathrm{~cm}^{-1}$ (characteristic to out-of-plane $\alpha \mathrm{C}-\mathrm{H}$ ) ring deformation ${ }^{39}$, disappeared in the copolymer spectrum (Figure 2 ), thus proving that the polymerization took place through the $\alpha$-positions of the thiophene rings. The carbonyl group from ester linkages, in both PEG and PCL side chains, appears centered at $1726 \mathrm{~cm}^{-1}$, whereas the methylene moiety next to the carbonyl group in PCL units can be visualized at $1192 \mathrm{~cm}^{-1}$. The copolymer composition was calculated using the ratio of the integrated area of the peak at $1726 \mathrm{~cm}^{-1}$ (belonging to both types of side chains) and the integrated area of the peak at 1192 $\mathrm{cm}^{-1}$ (typical to uniquely $\mathrm{PCL}$ side chains). The resulted copolymer composition calculated in this way was $61.5 \%$ Th$\mathrm{PCL} / 38.5 \%$ Th-PEG, that well agree with the composition values obtained by using NMR data. ${ }^{40,41}$ 

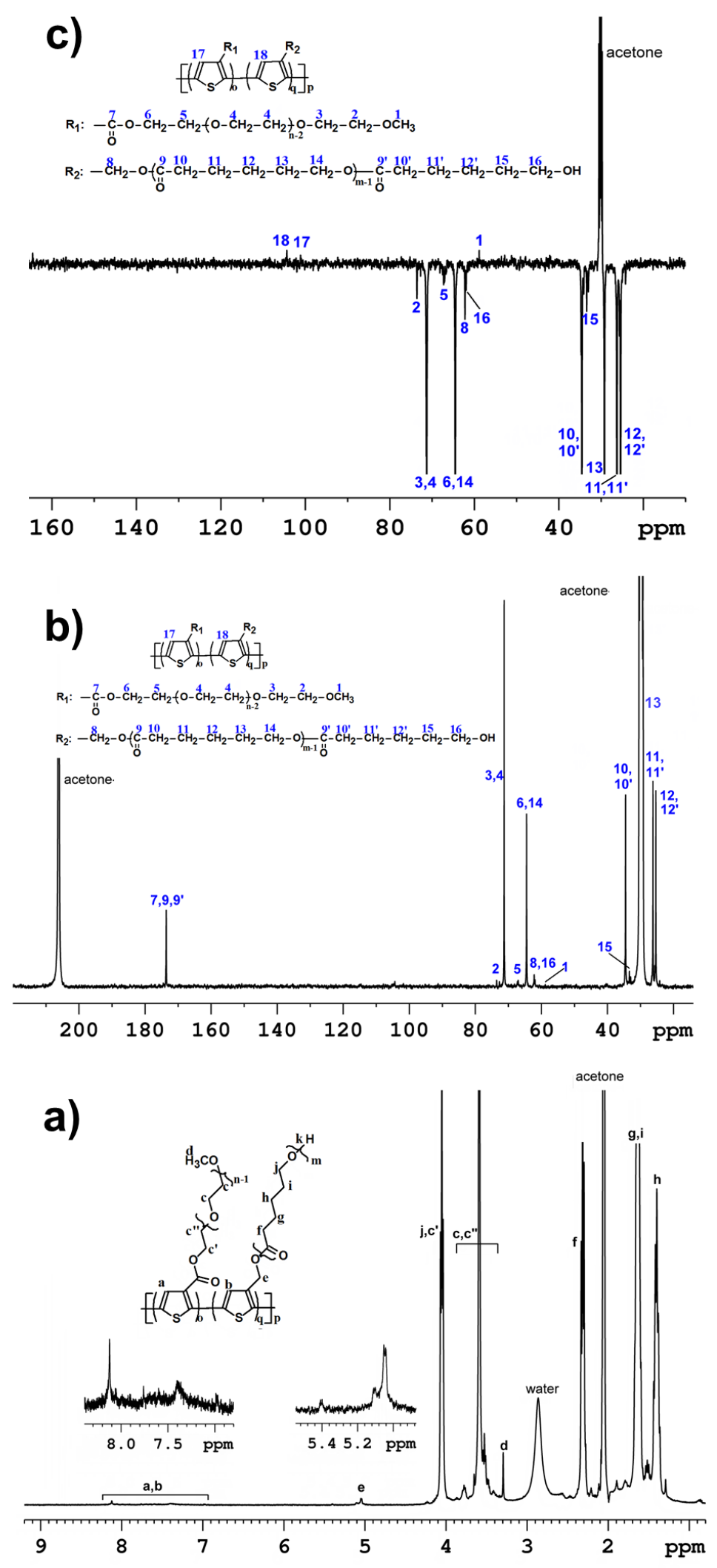

Figure 1. (a) ${ }^{1} \mathrm{H}-\mathrm{NMR}$, (b) ${ }^{13} \mathrm{C}-\mathrm{NMR}$ and (c) DEPT $135{ }^{13} \mathrm{C}-\mathrm{NMR}$ spectra of PTh- $g$-(PEG-r-PCL) copolymer, in acetone- $d_{6}$. $\mathrm{R}^{1}$ and $\mathrm{R}^{2}$ represent the PEG and PCL side groups. 


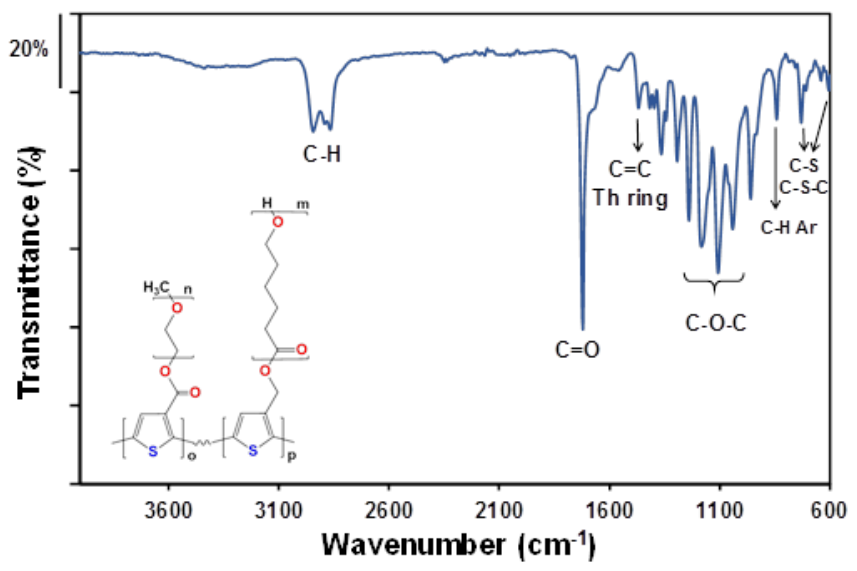

Figure 2. Infrared spectrum of PTh-g-(PEG-r-PCL) copolymer.

\subsection{The optoelectronic and electrochemical properties of PTh-g- (PEG-r-PCL) copolymer}

The photophysical properties of PTh-g-(PEG-r-PCL) copolymer were investigated by UV-vis and fluorescence spectroscopic measurements in acetone as good, non-selective solvent for the PEG and PCL side chains and as non-solvent for the polythiophene main chain (Figure 3). As it can be seen, the optical properties of the PTh backbone, were considerably affected by the presence of caprolactone oligomer side chains. In Figure 3a, a clear, sharp absorption band which is usually find in polythiophenes around 400 $\mathrm{nm}$, attributable to conjugated main chain, ${ }^{42}$ is missing and only three small shoulders are distinguishable at 370,400 and $470 \mathrm{~nm}$ (inset). This means that in the investigated acetone solution (dispersion) at least three types of chromophores exist, that most probable could be polythiophene chains with different conjugation chain length. Such absorption blurring phenomenon was also noticed for a conjugated fluorescent structure covalently connected to polycaprolactones chains. ${ }^{43}$ The authors attributed the observed blurring to the dispersed particles large size, which induced a light scattering effect. A similar reason for the less visible absorptions in the case of PTh- $g$-(PEG-r-PCL) could be taken into account, as DLS emphasized particles of high size.

In order to verify if the introduction of a PCL oligomer side chains also contribute to the noticed phenomenon, the behaviour of a grafted polythiophene with only PEG (Mw $\sim 2000 \mathrm{~g} / \mathrm{mol}$ ) side chains, (PTh-g-PEG ${ }_{2000}$ ) which was previously reported as being synthesized by Yamamoto polycondensation, ${ }^{37}$ was analyzed in similar conditions (black lines in Figure 3). Unlike PTh-g-(PEG-r-PCL), PTh- $g$ - PEG $_{2000}$ shows a pronounced, high intense absorption band centred at 415 $\mathrm{nm}$ and an emission one at $550 \mathrm{~nm}$ when excited with $400 \mathrm{~nm}$ wavelength. This means that the PCL oligomer side chains in the composition of PTh-g-(PEG-r-PCL) copolymer is one of the reasons of the observation of such absorption blurring phenomenon. However, when excited with $400 \mathrm{~nm}$, PTh-g-(PEG-r-OCL) copolymer shows a more intensive fluorescent emission band, with a maximum approximately $100 \mathrm{~nm}$ blue shifted in comparison with PTh- $g$ $P E G_{2000}$. This blue shift could be attributed to the presence of electron withdrawing carbonyl moieties in the structural units of caprolactone side chains that are responsible for a such effect as it was well documented in the previous report. ${ }^{37}$
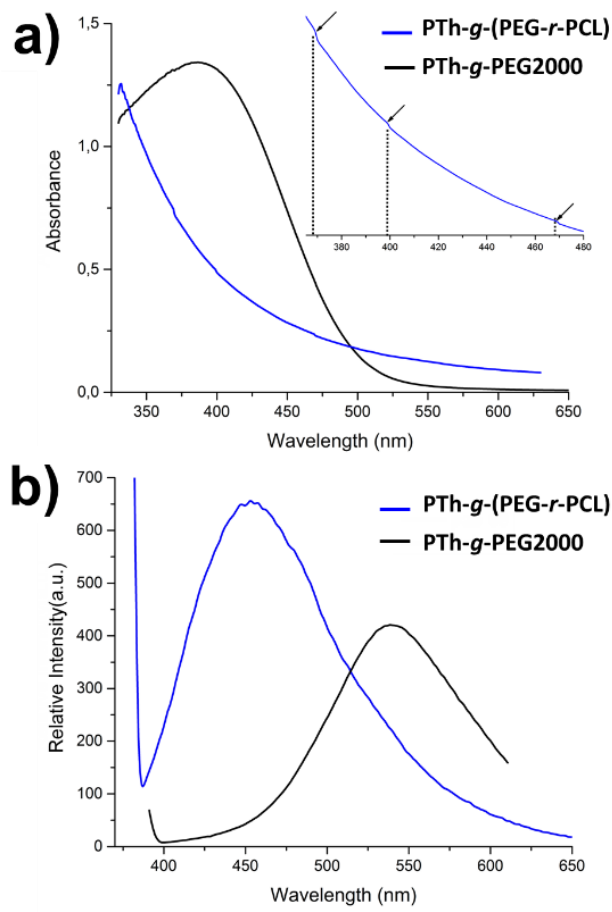

Figure 3. UV-vis (a) and fluorescence (b) spectra of random copolymer compared to previously reported PTh-g-PEG2000, ${ }^{37}$ in acetone at concentration of $1 \mathrm{mg} / \mathrm{ml} ; \lambda$ ex=400 $\mathrm{nm}$.

The electroactivity and electrostability of the solid PTh-g(PEG-r-PCL) copolymer, deposited by solvent casting onto carbon electrodes (DS 150), were evaluated with cyclic voltammetry. Experiments were conducted in PBS solution, which mimicked a physiological electrolytic medium. Figure 4a compares the voltammetric curves of the bare electrode and the PTh- $g$-(PEG-r-PCL) copolymer at a scan rate of $50 \mathrm{mV} \cdot \mathrm{s}^{-1}$. Although the current density of PTh- $g$-(PEG-r-PCL) is low, it is much higher than that of carbon electrode. This indicates that the charge storing capacity is significantly higher for the PTh- $g$ (PEG-r-PCL) graft copolymer than for the carbon electrode, even after 25 cycles (dashed line in Figure 4a).

Figure $4 \mathrm{~b}$ represents the loss of electroactivity for PTh-g(PEG-r-PCL) after several consecutive oxidation-reduction cycles. As it can be seen, the electroactivity decreased only $0.13 \%$ after 25 cycles, evidencing that the polymer is very stable to redox processes. In addition, voltammetry curves recorded at different scan rates (from 20 to $200 \mathrm{mV} \cdot \mathrm{s}^{-1}$ ) were collected to check the response of the copolymer to the variable sweep rate (Figure 4c). The increase of peak current density with the scan rate evidences a good kinetics of the copolymer interfacial redox properties and the improvement of the ionic charge transport, even at high rates. Thus, these results reflect that the redox behaviour of PTh-g-(PEG-r-PCL) shows an excellent rate capability. ${ }^{39}$ 

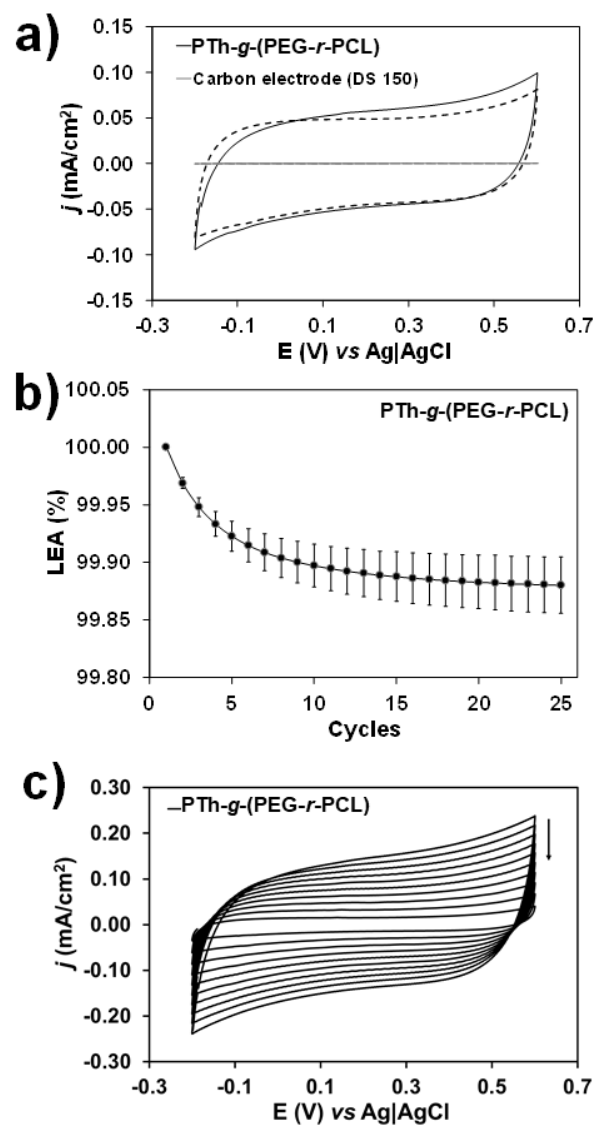

Figure 4. a) Cyclic voltammograms of PTh-g-(PEG-r-PCL) in PBS solution. b) Loss of electroactivity (LEA, \%) with the number of redox cycles. c) cyclic voltammograms of PTh-g-(PEG-r-PCL) in PBS solution at different san rates $\left(200,180,160,140,120,100,80,60,40\right.$ and $\left.20 \mathrm{mV} \cdot \mathrm{s}^{-1}\right)$. In a) the solid and dashed lines correspond to the $1^{\text {st }}$ and the $25^{\text {th }}$ oxidation-reduction cycle.

\subsection{Influence of the solvent on the morphology of amphiphilic PTh-g-(PEG-r-PCL) copolymer}

All together, the experimental results suggest that the polythiophene main chain form a central solid-like hydrophobic core, while the side chains can function as a sheath. However, the presence of the self-assembled structures in solution and their morphology characterization in solid state are both necessary.

In order to understand copolymer-solvent interaction and whether its chains are intermolecular associated or not, due to non-covalent supramolecular interactions, a dynamic light scattering (DLS) study in acetone was performed and the results are presented in Figure S4. DLS measurement shows the presence of three types of supramolecular aggregates, with size varying from $976 \mathrm{~nm}$ to $31 \mu \mathrm{m}$ and to $146 \mu \mathrm{m}$. The results of this analysis must be considered with care as it is based on the assumptions that the particles are non-interacting sphere and not anisotropic objects, and the particle size is the diameter of the sphere diffusing at the same speed as the particles being measured. ${ }^{36}$

Taking into account that, on the one hand, the acetone is a good solvent for both side chains and, on the other hand, the hydroxyl groups of the PCL chains-end could form hydrogen bonds with this solvent, stabilizing in this way the polymersolvent interaction; it can be supposed that PTh- $g$-(PEG-r-PCL) chains, in acetone solution, exist in molecularly well-dissolved state. The size of these chains with longer or shorter- $\pi$ conjugated main chains could be too small to be "sensed" by DLS technique. However, as acetone is a low hydrogen-bonding acceptor, besides these well-dissolved copolymer chains, it cannot be excluded the presence of micelles-like supramolecular aggregates, formed due to intermolecular interaction, as a result of the competition between polymerpolymer and polymer-solvent interaction. The multichains aggregation can be favored and enhanced by a synergistic combination of $\pi-\pi$ stacking from thiophene units ${ }^{44-46}$ and intermolecular PCL hydrogen bonding. As concluded from NMR investigation, the copolymer chains exist as core-lengthwisesegregated sheath structures that can form intermolecular $\pi-\pi$ stacks because PEG side chains in the hydrophilic half-sheath may be too short and/or too loosely grafted to prevent the main chains interaction. All of these can explain the obtained results by DLS.

Therefore, SEM and TEM accurate analyses should be performed. It is worthy to mention that, generally, the changing from the solution to the dry state is a very complex phenomenon due to the many influencing factors that can act on the shape and size of such compounds. TEM micrographs displayed in Figures 5a-c show the round-like morphology of the copolymer with irregular sizes, corresponding to nano- and microparticles, as detected by DLS. After treatment with uranyl acetate, which is usually employed to observe non conducting materials in TEM, differentiation on material nature were revealed. Some spherical microparticles (black and without shell cover) were observed when the sample does not have the uranyl staining (Figures 5a-b). In contrast, a clear thin layer different from the core, which has been attributed to the PEG or PCL chains, is observed in TEM micrographs when the samples are treated with uranyl staining (Figure $5 \mathrm{c}$ ). This proves that the core of those particles corresponds to the conjugated thiophene polymer backbone. Regarding the particle diameter (Figure 5d), a heterogeneous distribution with values ranging from 300 to $900 \mathrm{~nm}$ is observed, the average value being $569 \pm$ $130 \mathrm{~nm}$. Different contrasts were also observed in TEM micrographs of core-shell self-assembled particles formed by CPs and insulating polymers, as for example those involving polyaniline and polyacrylates. ${ }^{47}$ However, in that particular case, the CP was located in the shell instead of the core. 

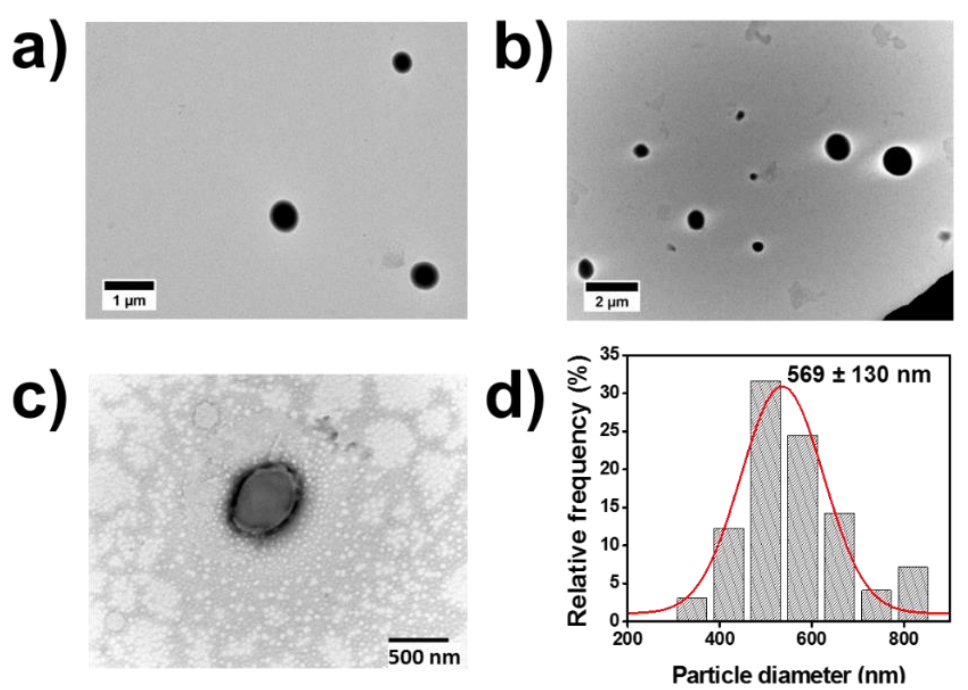

Figure 5. TEM micrograph of PTh- $g$-(PEG- $r$-PCL): $a-b)$ spherical particles detected without uranyl acetate staining, $c$ ) with uranyl acetate staining; and d) size particle distribution measured with dilute acetone solution.

Rod-coil structures were also carefully observed by TEM, with further experiments carried out with very low concentration of the new copolymer in acetone solution 10.004 $\mathrm{mg} / \mathrm{mL}$ ). Therefore, in Figure 6 , the rod- and spherical-like morphologies were detected, among others. As for example, straight rods, horseshoe- and pseudospherical-like structures (formed for the longer or shorter PTh main chain, respectively) are also discernible in Figures $6 \mathrm{~b}-\mathrm{c}$ due to the well-known phenomenon of spontaneous curvature which is taking place in the case of heterografted, statistical copolymers adsorbed at interfaces and during draying process. ${ }^{48,49}$

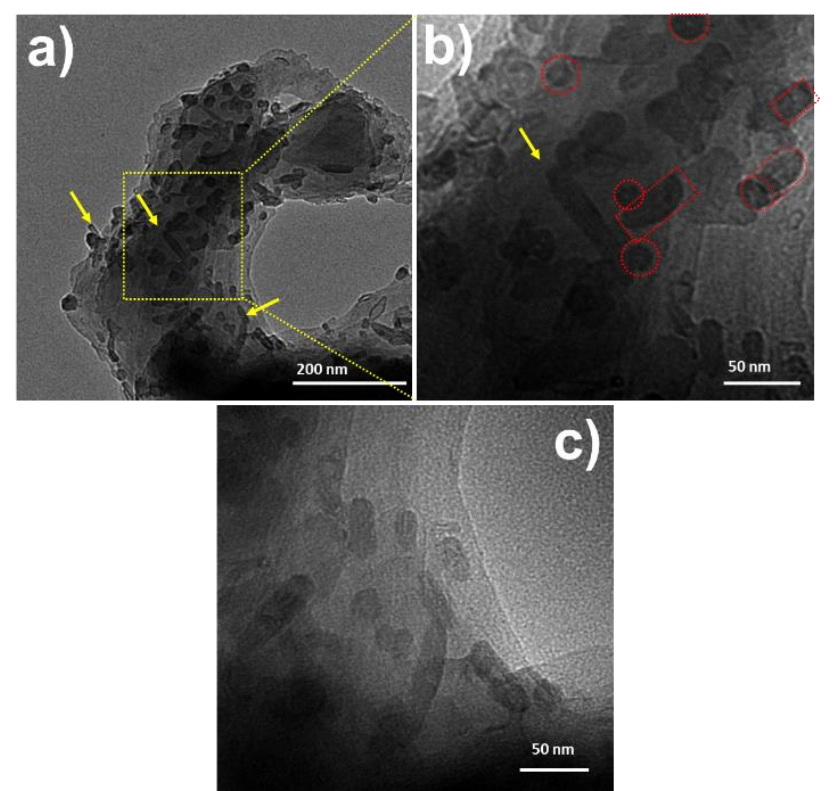

Figure 6. TEM micrograph of PTh-g-(PEG-r-PCL) obtained from a solution of $0.004 \mathrm{mg} / \mathrm{mL}$ in acetone solvent, in unstained form. Rod like structures are highlighted with yellow arrows in a) low magnification and b-c) high magnifications images with straight rods, horseshoe- and pseudosphericallike structures highlighted with spherical and rectangular forms in red, in figure b).
On the other hand, SEM micrographs (Figure 7a-c) mainly evidenced the presence of spherical and porous particles, with very scattered sizes, and few amount of rod-like small structures. As it can be seen, such particles adopt an irregular spherical-like shape with high variability in diameter and porosity (Figure 7b) with some agglomeration. Thus, the heterogeneous morphology seen in Figures $7 a-c$ can be attributed to several factors: (i) the fast evaporation of the solvent, which causes the appearance of aggregates; (ii) the backbone polydispersity (molecular weight); and (iii) the heterogeneous length of the conjugated main chain and the side chains.

Moreover, the EDX spectrum displayed in Figure 7d shows the presence of only $\mathrm{C}$ and $\mathrm{O}$ atoms, evidencing that the outer layer is constituted by the PEG/PCL branches. The sulphur atoms coming from the PTh backbone were hardly observed by EDX, confirming that the tiophene units are enclosed inside the spheres, as was observed above by TEM, keeping the structure formed in solution, as deduced from NMR registration. ${ }^{37}$

In conclusion, the solvent and the concentration of the copolymer used for this study decisively influenced the intra- and intermolecular forces on polymer chains and among particles, in a such a way to drive the appearance of the new type of structures during the solvent evaporation. In Figure 8, such SA structures are depicted and represents a good approach for the experimental results found in this work. 


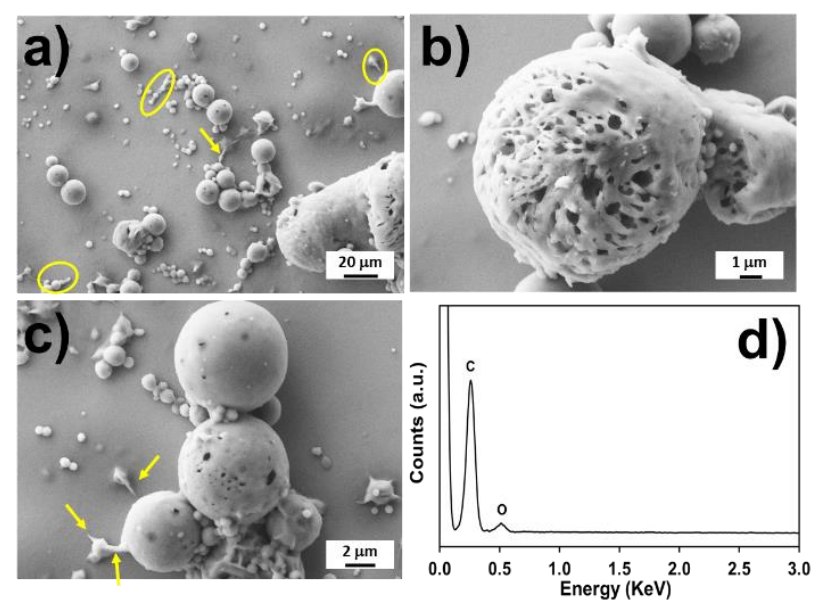

Figure 7. SEM micrographs of PTh-g-(PEG-r-PCL) microspheres (a-c); and EDX spectrum (d), from spherical particle showed in c). Arrows and circles indicate the rod-coil structures.

Therefore, the rod-like structure can be the result of the aggregates formed in solution by intermolecular multichains SA of the enough long main chains-containing molecules (Figure 8a), which even after solvent evaporation are able to keep their rod shape. The presence of the spherical particles, can be due by the copolymer molecules having a shorter main chain and even shorter than the side chains (Figure $8 b$ ). The transition from the linear-like shape to spherical shape start from the collapse of the side chains onto copolymer main backbone causing the backbone to undergone the axial contraction under a limit value and the linear branched architecture will eventually transform into a spherical one, as reported elsewhere. ${ }^{50}$

a)
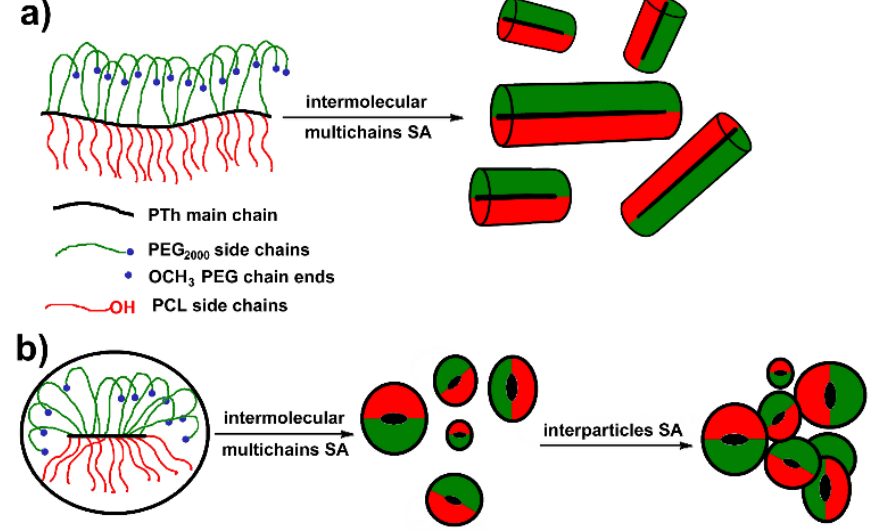

Figure 8. Schematic representation of the scenario for copolymer PTh-g-(PEG$r$-PCL) self-assembling in both acetone solution and in thin film: (a)-for longer PTh main chains and (b) for short PTh main chains.

\subsection{Study of PTh-g-(PEG-r-PCL) copolymer as sensor for NADH reactions}

$\mathrm{NADH}$ is a vital coenzyme for metabolic redox reactions. NADH losses two electrons and delivers a hydrogen ion, as it becomes oxidized to NAD+ (Figure 9a). As the main role of $\mathrm{NADH}$ and $\mathrm{NAD}^{+}$in the metabolism is the transfer of electrons from one molecule to another, the balance between such oxidized and reduced species is called the NAD $/ \mathrm{NADH}$ ratio. This ratio is an important parameter to certify the correct metabolic activity and the health status of the cells, among other functions.

Figure $9 \mathrm{~b}$ shows the voltammetric curve obtained for $10 \mathrm{mM}$ of NADH solution at $50 \mathrm{mV} \cdot \mathrm{s}^{-1}$. As it can be seen, the grafted copolymer is able to catalyse the oxidation of NADH molecules in PBS $(\mathrm{pH}=7.4)$ and the resulting oxidation potential is detected at $\sim 0.6 \mathrm{~V}$, which agrees with the value reported in the literature. ${ }^{28}$ Figure $9 c$ shows the differential pulse voltamogramms (DPV) for a PBS solution with different concentrations of NADH (from 2 to $10 \mathrm{mM}$ ). Results evidence that the copolymer catalyses the oxidation of NADH with good current density response in a low potential range. Even when the anodic peak current decreases with the concentration of $\mathrm{NADH}$, the peak potential remains almost constant between 0.62-0.65 V, for all concentrations. Moreover, the calibration curve (Figure $9 \mathrm{~d}$ ) shows a good linear behaviour, the regression coefficient being 0.9801 .

The performance of copolymer as amperometric sensor for the detection of very low NADH concentrations has been also evaluated. The amperometric current density-time (j-t) response against the addition of $\mathrm{NADH}$ and the corresponding calibration plot are shown in Figures 9 e-f. A linear relationship with a regression coefficient of 0.9873 was obtained for NADH concentration interval between 0.2 to $2 \mathrm{mM}$ (Figure 9f). We attribute such sensor ability to the unusual topology of the copolymer, that is independent from the heterogeneous microparticle size, but with a positive influence of the presence of porous, that could allow the permeation of NADH molecules to the thiophene inner units.

In summary, the prepared amphiphilic heterografted polythiophene copolymer containing PEG and PCL side chains has been proved to detect NADH. This sensing capacity is simply achieved by depositing the copolymer microparticles onto a carbon electrode via drop-casting. After optimization of the sensor, the sensibility of PTh- $g$-(PEG-r-PCL) to low NADH concentrations can be used in future studies for the quantitative determination of $\mathrm{NAD+} / \mathrm{NADH}$ ratio in living cells.

Having in mind the good sensitivity for low NADH concentrations, the sensibility of PTh-g-(PEG-r-PCL) particles to detect NADH oxidation was evaluated in the presence of interfering species. $A A$ is the most common interfering compound in the electrochemical detection of $\mathrm{NADH}$ from biological samples. ${ }^{51}$ Accordingly, the selective determination of NADH in a mixture with AA was conducted using both CV and DPV. Figure 10a shows the voltammetric curve recorded for PTh- $g$-(PEG-r-PCL) in a $0.1 \mathrm{M}$ of PBS solution with of $5 \mathrm{mM}$ of AA and $5 \mathrm{mM}$ of $\mathrm{NADH}$. Two main oxidation peaks, which have been attributed to the oxidation of AA (lower potential) and NAD+ process, are clearly detected. The differential pulse voltammogram, which is displayed in Figure $10 \mathrm{~b}$, presents two well defined oxidation peaks at 300 and $580 \mathrm{mV}$ that correspond to AA and NADH, respectively. Moreover, the peak 
separation of $280 \mathrm{mV}$ indicates that the amphiphilic PTh grafted copolymer can be successfully used for selective detection of $\mathrm{NADH}$ in the presence of AA. ${ }^{51}$

\subsection{Biocompatibility of PTh-g-(PEG-r-PCL) copolymer}

The biocompatibility of PTh- $g$-(PEG-r-PCL) copolymer was evaluated by cell adhesion (after one day) and proliferation (after 7 days) assays. Due to their fast growth, fibroblast (Cos-1) and epithelial (Vero) cell lines were selected. Figure 11a shows the quantitative results of cell viability, steel being used as control substrates. Quantification of cell adhesion onto copolymer surface reveals higher viabilities than those of the steel control substrates, for both types of cell lines $\left(160 \% / \mathrm{cm}^{2}\right.$ and $120 \% / \mathrm{cm}^{2}$ for Cos-1 and Vero cells, respectively). Thus, for short period of time (24 h) PTh-g-(PEG-r-PCL) copolymer do not show any cytotoxic effects acting as excellent supportive matrices, especially for the Cos-1. After seven days of culture, a slight reduction of the relative cell viability ( $12 \%$ for Cos- 1 and $30 \%$ for Vero cells) on PTh- $g$-(PEG-r-PCL) in comparison to steel was recorded (Figure 11a).

In our previous studies, ${ }^{33}$ when a PEG-homosubstituted polythiophene (PTh-g-PEG 2000 ) having a hydrophilic/lipophilic balance (HLB) of 0.82 was investigated, increased values for both adhesion $\left(128 \% / \mathrm{cm}^{2}\right)$ and proliferation $\left(131 \% / \mathrm{cm}^{2}\right)$ of Vero cells, in relation to the steel, were obtained. This behavior had been interpreted as a positive contribution of the grafted hydrophilic PEG side chains, which significantly decrease the bare PTh cytotoxicity by decreasing its hydrophobicity. It is generally agreed that hydrophilicity of substrates positively affect biological response, such as cell adhesion and proliferation. ${ }^{52}$ On the one hand, it is well-recognized the poor adhesion of cells to the typically hydrophobic, neutrally charged, and low-surface energy semiconducting thin films. ${ }^{53}$ In the specific case of PTh-g-(PEG-r-PCL) copolymer, with a composition of $40 \%$ of Th-PEG and $60 \%$ of Th-PCL, the HLB is only $0.36 ;{ }^{38}$ resulting in a high hydrophobic material. In a recent report, 54 about the fact that pure PCL significantly decreases the viability of Vero cells, it could also be associated and could explain the reduction of cells proliferation on PTh- $g$-(PEG-r-PCL) copolymer surface, found in the present work.

The SEM images (Figures $11 \mathrm{~b}-\mathrm{c}$ ) demonstrate the usually normal growth and morphology of Cos-1 and Vero cells, respectively, onto PTh- $g$-(PEG-r-PCL), after one week of incubation. It is well known that normal fibroblasts or epithelial cells, excepting adhesion, necessitate also an efficient spreading on the substrate for growth in vitro. ${ }^{55}$ The obtained results induced the conclusion that PTh- $g$-(PEG- $r$-OCL) microspheres surface properties highly stimulate adhesion of cells but subsequently the cells are most probably inhibited from spreading, resulting in a lower proliferation observed after 7 days. However, as the cell morphology is a useful indicator of a material biocompatibility ${ }^{56}$ and the SEM micrographs displayed show an unaltered normal growth; it allow to consider that, most probable, the reduction of cellular proliferation is a consequence of heterogeneous microscale surface topography combined with a certain surface chemistry of PTh- $g$-(PEG-r-PCL) copolymer.

The correlation between the physiochemical properties of a biomaterial and cellular behaviors is still far from definitely understanding and unanimous conclusion could not yet be given. ${ }^{57}$ Moreover, even if PEG and PCL are both FDA approved biocompatible polymers, ${ }^{58}$ the effect of their incorporation in bioactive polymeric materials can be significant and complex; especially when the effect on cells fate is considered. ${ }^{59}$ In this context, a future study about the synergies among surface morphology, chemistry composition and free surface energy optimization will be performed. For PTh-g-(PEG-r-PCL) copolymer, all of these parameters can be modulated by a combination of solvent polarity, concentration and processing (drop-casting or spin-coating), in order to improve and also to regulate its biocompatibility. 
a)
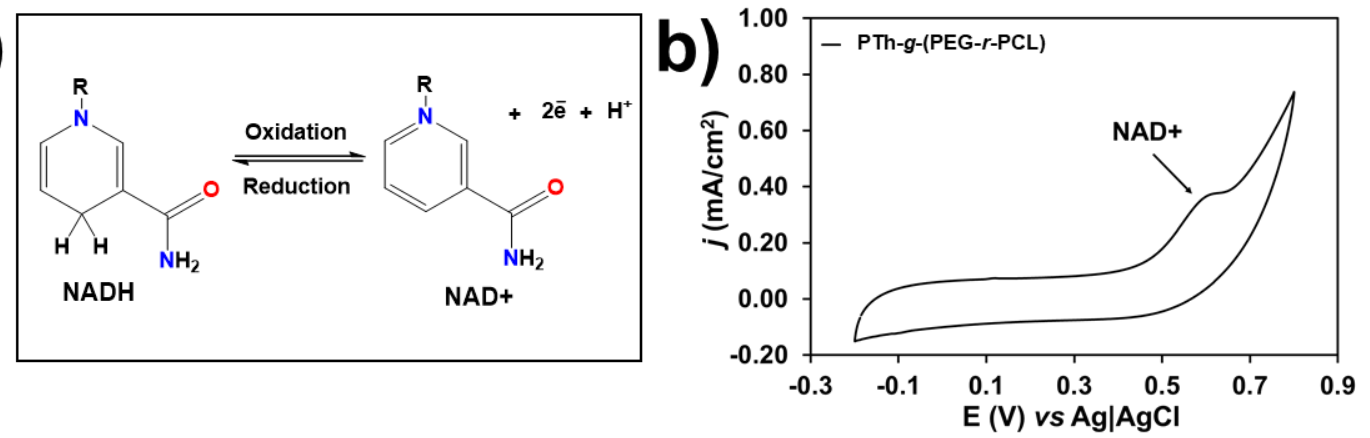

c)

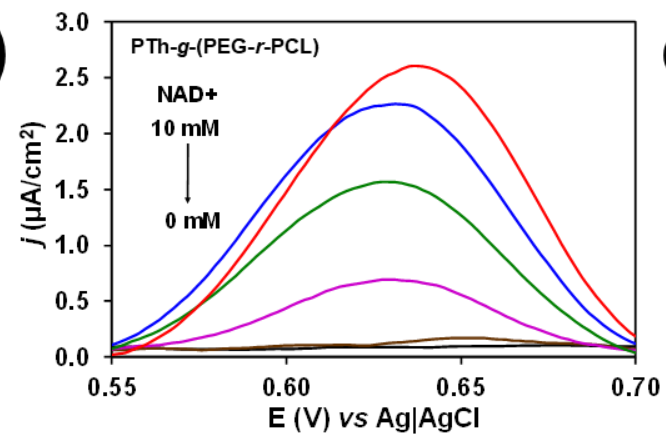

e)

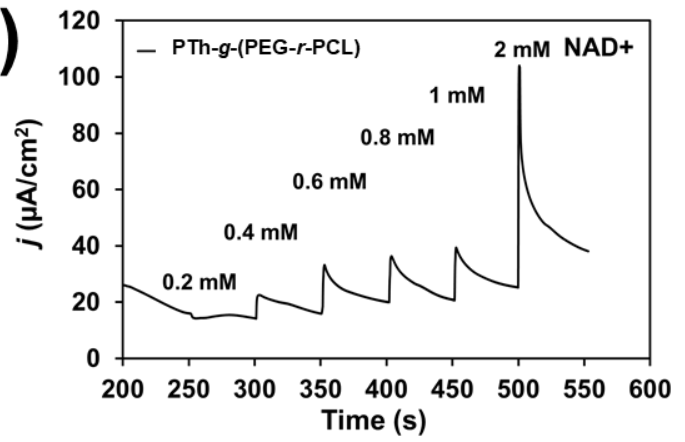

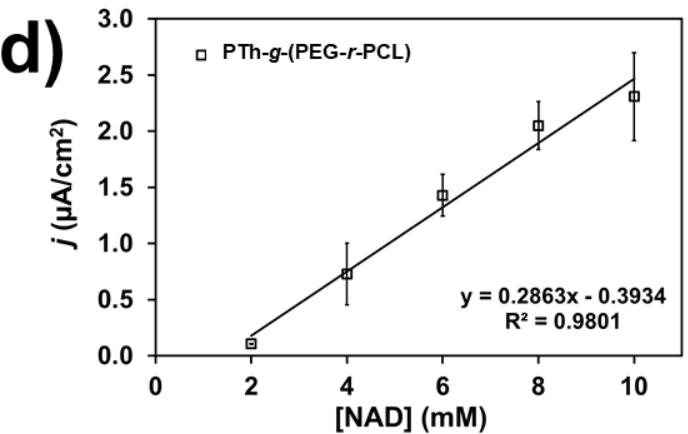

f)

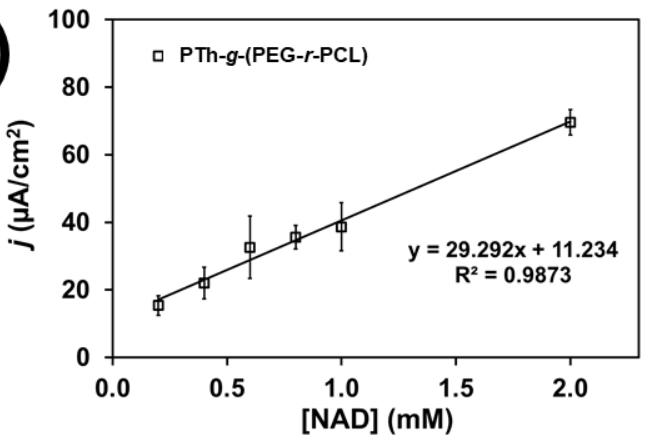

Figure 9. a) Redox $\mathrm{NADH} / \mathrm{NAD}^{+}$reaction. b) Cyclic voltammogram of $\mathrm{PTh}-g-(\mathrm{PEG}-\mathrm{r}-\mathrm{PCL})$ in a PBS solution containing $10 \mathrm{mM} \mathrm{M} \mathrm{NADH}\left(\mathrm{scan}\right.$ rate= $\left.\left.50 \mathrm{mV} \cdot \mathrm{s}^{-1}\right) . \mathrm{c}\right)$ DPV obtained for PBS solutions ( $\mathrm{pH}=7.4$ ) containing a NADH concentration comprised between $2 \mathrm{mM}$ and $10 \mathrm{mM}$. $\mathrm{d}$ ) Calibration curve for the NADH detection in a concentration range from 2 to $10 \mathrm{mM}$ using the PTh- $g$-(PEG-r-PCL) copolymer. e) Current density-time responses of PTh- $g$-(PEG-r-PCL) upon successive injection of a given concentration of $\mathrm{NADH}$ into the PBS solution $(\mathrm{pH}=7.4)$. $\mathrm{f}$ ) Calibration curve for the NADH detection in a concentration range from 0.2 to 2 $\mathrm{mM}$ using PTh-g-(PEG- $r$-PCL). 

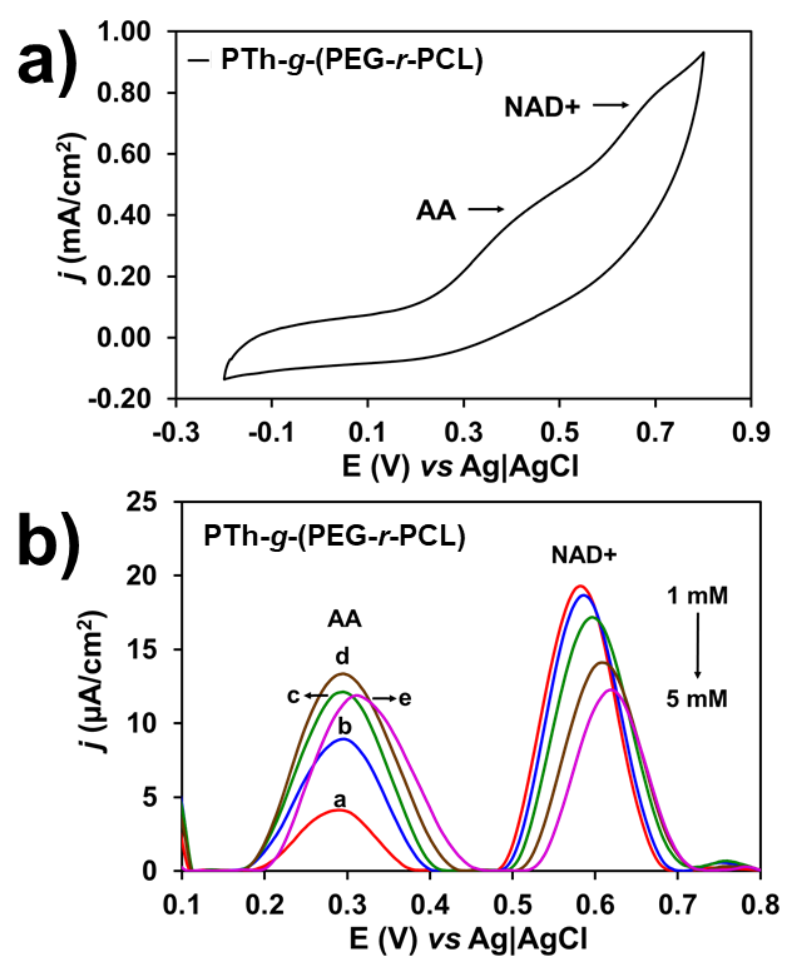

Figure 10. a) Cyclic voltammogram obtained for PTh- $g$-(PEG-r-PCL) in a PBS solution with $5 \mathrm{mM} \mathrm{NADH}$ and $5 \mathrm{mM} \mathrm{AA}$. Scan rate: $50 \mathrm{mV} \cdot \mathrm{s}^{-1}$. b) Differential pulse voltammogram obtained for PTh- $g$-(PEG- $r$-PCL) in a PBS solution with $5 \mathrm{mM} \mathrm{NADH}$ and a variable concentration of AA (from the lowest, $a=1 \mathrm{mM}$; to the highest concentration, $\mathrm{e}=5 \mathrm{mM}$ ).

\section{a)}
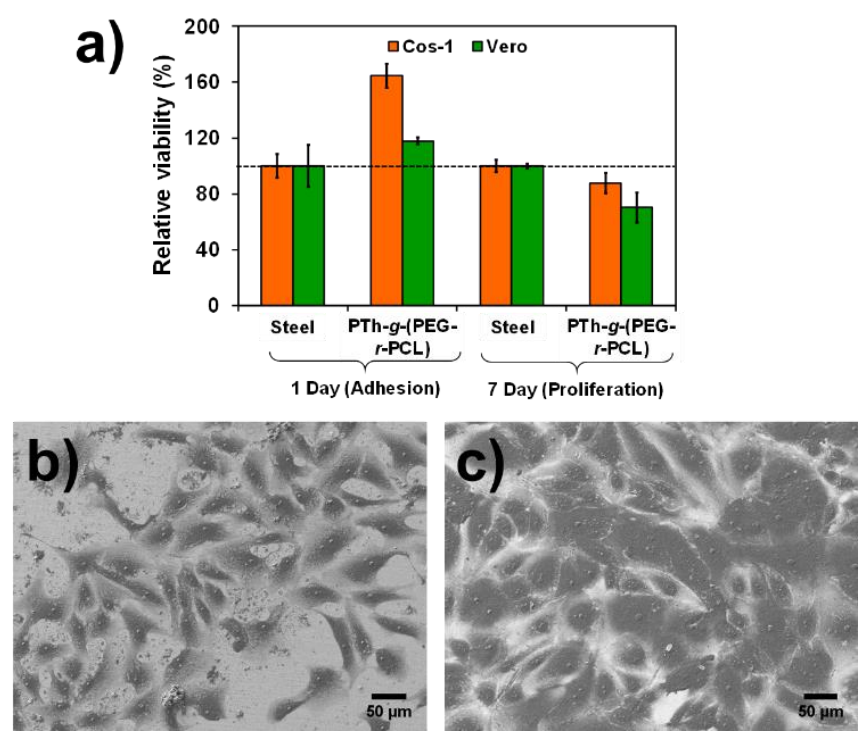

Figure 11. a) Cellular adhesion and proliferation for PTh- $g$-(PEG-r-PCL) amphiphilic copolymer using Cos-1 and Vero cells; b) Cos-1 cells and c) Vero cells observed with SEM microscope, after incubation for 7 days.

\section{Conclusions}

By oxidative polycondensation method of an equimolar mixture of PEG-containing thiophene macromonomer (Th-PEG) and OCL-containing thiophene macromonomer (Th-OCL), amphihilic PTh- $g$-(PEG-r-PCL) copolymer was synthesized using "bottom-up" type construction strategy. The resulting material, so-called prototype or Janus type copolymer, has a hydrophiliclipophilic balance (HLB) of 0.36 and a copolymer composition of $40 \%$ of Th-PEG and $60 \%$ of Th-OCL, as proved by NMR spectroscopy. The morphology study, from copolymer solutions in acetone, revealed the obtaining of spherical microparticles with heterogeneous size and porosity. The deposition of such microspheres onto carbon electrodes evidenced the ability of the $\pi$-conjugated system to detect the oxidation reaction of $\mathrm{NADH}$ coenzyme molecules, with lineal response, dependent on the increase concentration of the coenzyme.

The investigations of the copolymer properties, in acetone solution, revealed several phenomena: (i) copolymer undergone intra-and/or intermolecular microphase separation resulting in supramolecular entities of multiple size, demonstrated by DLS measurements and microscopy; (ii) a blurring of PTh main chain absorption, evidenced by UV-vis spectroscopy, which is most probable due to the presence of $\mathrm{PCL}$ oligomer side chains and to the high values of the particles size; (iii) an increased intensity and a blue shift of fluorescence maximum by comparing with its PEG-monosubstituted homologous.

In conclusion, by intelligently combining the components of well-known polymeric biomaterials (PEG and PCL) with a multisensitive conjugated polymer (PTh), a biomimetic material was obtained. Its biomimicry is reflected in its amphiphilicity similitude and in its self-assembling ability. The presence of PCL side chains strengthened the electrochemical stability and increased the ionic conductivity, endowing the copolymer with high ability to work in aqueous electrolytes.

\section{Conflicts of interest}

There are no conflicts to declare.

\section{Acknowledgements}

This work was supported by Spanish and Romanian funding agencies. In Spain, MINECO (RTI2018-098951-B-I00) and the Agència de Gestió d'Ajuts Universitaris i de Recerca (2017SGR359) are grateful acknowledged. In Romania, this work was supported by a grant of Ministery of Research and Innovation, CNCS-UEFISCDI (PN-III-P4-ID-PCCF-2016-0050, within PNCDI III), for which the Romanian authors greatly acknowledge. Support for the research by C. A. was received through the prize "ICREA Academia 2015" for excellence in research, funded by the Generalitat de Catalunya (CataloniaSpain). B. G. M. is thankful to CONACYT agency for their financial support through a postgraduate scholarship (328467 CVU 621314) 


\section{Notes}

$\S$ Both authors contributed equally.

\section{References}

1

G. Verma and P. Hassan, in Trends in Biomaterials, ed. G.P. Kothiyal and A. Srinivasan, CRC Press, Taylor and Francis Group, Boca Raton, 2016, pp. 49-84. F. Huang, R. O'Reilly and S. C. Zimmerman, Chem. Commun., 2014, 50, 13415-13416. G. Saravanakumar, H. Park, J. Kim, D. Park, S. Pramanick, D. H. Kim and W. J. Kim, Biomacromolecules, 2018, 19, 22022213. S. Biswas, P. Kumari, P. M. Lakhani and B. Ghosh, Eur. J. Pharm. Sci., 2016, 83, 184-202.

5 Y. Liang, X. Deng, L. Zhang, X. Peng, W. Gao, J. Cao, Z. Gu and B. He, Biomaterials, 2015, 71, 1-10. L. Gao, X. Lin, X. Hai, X. Chen and J. Wang, ACS Appl. Mater. Interfaces, 2018, 10, 43049-43056. 3168. S. Huang, X. Wei and M. Wang, Polymers (Basel)., 2018, 10, 1120. Z. Ruan, L. Liu, L. Fu, T. Xing and L. Yan, Polym. Chem., 2016, 7, 4411-4418.

\section{4, 8205-8214.} J. Lü, Y. Yang, J. Gao, H. Duan and C. Lü, Langmuir, 2018, 2015, 119, 1960-1970

F. Cheng, T. Su, K. Luo, Y. Pu and B. He, J. Mater. Chem. B, 2019, 7, 1005-1016.

L. T. Strover, J. Malmström and J. Travas-Sejdic, Chem. Rec., 2016, 16, 393-418.

S. Maione, G. Fabregat, L. J. del Valle, A.-D. Bendrea, L. Cianga, I. Cianga, F. Estrany and C. Alemán, J. Polym. Sci. Part B Polym. Phys., 2015, 53, 239-252.

E. W. C. Chan, P. Baek, D. Barker and J. Travas-Sejdic, Polym. Chem., 2015, 6, 7618-7629.

F. Liu, X. Zhao, X. Zhang, X. Zhang, J. Peng, H. Yang, K. Deng, L. Ma, C. Chang and H. Wei, Polym. Chem., 2018, 9, 48664874.

N. Yi and M. R. Abidian, Conducting polymers and their biomedical applications, 2015.

T. P. Kaloni, P. K. Giesbrecht, G. Schreckenbach and M. S. Freund, Chem. Mater., 2017, 29, 10248-10283. M. A. Woodruff and D. W. Hutmacher, Prog. Polym. Sci., 2010, 35, 1217-1256. L. Chang, J. Liu, J. Zhang, L. Deng and A. Dong, Polym. Chem., 2013, 4, 1430-1438.

W. Qi, P. P. Ghoroghchian, G. Li, D. A. Hammer and M. J. Therien, Nanoscale, 2013, 5, 10908-10915.

W. Wang, H. Sun, F. Meng, S. Ma, H. Liu and Z. Zhong, Soft Matter, 2012, 8, 3949-3956.

J. Yan, Z. Ye, M. Chen, Z. Liu, Y. Xiao, Y. Zhang, Y. Zhou, W. Tan and M. Lang, Biomacromolecules, 2011, 12, 25622572. Y. Tian, W. C. Wu, C. Y. Chen, T. Strovas, Y. Li, Y. Jin, F. Su, D. R. Meldrum and A. K. Y. Jen, J. Mater. Chem., 2010, 20,
26

27

1728-1736.

M. L. Gou, L. Zheng, X. Y. Peng, K. Men, X. L. Zheng, S. Zeng, G. Guo, F. Luo, X. Zhao, L. J. Chen, Y. Q. Wei and Z. Y. Qian, Int. J. Pharm., 2009, 375, 170-176.

Z. Li and B. H. Tan, Mater. Sci. Eng. C, 2014, 45, 620-634. A. D. Bendrea, G. Fabregat, J. Torras, S. Maione, L. Cianga, L. J. Del Valle, I. Cianga and C. Alemán, J. Mater. Chem. B, 2013, 1, 4135-4145.

B. G. Molina, A. D. Bendrea, L. Cianga, E. Armelin, L. J. Del Valle, I. Cianga and C. Alemán, Polym. Chem., 2017, 8, 6112-6122.

B. G. Molina, L. Cianga, A. D. Bendrea, I. Cianga, L. J. Del Valle, F. Estrany, C. Alemán and E. Armelin, Polym. Chem., 2018, 9, 4218-4232.

Y. Liu, H. Hou and T. You, Electroanalysis, 2008, 20, 17081713.

S. Jayabal and R. Ramaraj, J. Appl. Electrochem., 2015, 45, 881-888.

S.-M. Chen and S. A. Kumar, Sensors, 2008, 8, 739-766.

A. Levent Demirel, S. Yurteri, I. Cianga and Y. Yagci, J. Polym. Sci. Part A Polym. Chem., 2007, 45, 2091-2104. S. Marina, D. Mantione, K. ManojKumar, V. Kari, J. Gutierrez, A. Tercjak, A. Sanchez-Sanchez and D. Mecerreyes, Polym. Chem., 2018, 9, 3780-3790. A. C. Da Silva, A. T. S. Semeano, A. H. B. Dourado, H. Ulrich and S. I. Cordoba De Torresi, ACS Omega, 2018, 3, 55935604.

D. G. Colak, I. Cianga, L. Cianga and Y. Yagci, Des. Monomers Polym., 2016, 19, 508-534.

L. Cianga, A. D. Bendrea, N. Fifere, L. E. Nita, F. Doroftei, D. Ag, M. Seleci, S. Timur and I. Cianga, RSC Adv., 2014, 4, 56385-56405.

H. Liu, A. Jiang, J. Guo and K. E. Uhrich, J. Polym. Sci. Part A Polym. Chem., 1999, 37, 703-711.

R. B. Ambade, S. B. Ambade, N. K. Shrestha, R. R. Salunkhe, W. Lee, S. S. Bagde, J. H. Kim, F. J. Stadler, Y. Yamauchi and S. H. Lee, J. Mater. Chem. A, 2017, 5, 172-180.

A. D. Bendrea, G. Fabregat, L. Cianga, F. Estrany, L. J. Del Valle, I. Cianga and C. Alemán, Polym. Chem., 2013, 4, 2709-2723.

T. P. Tuyen Dao, T. H. Nguyen, V. V. To, T. H. Ho, T. A. Nguyen and M. C. Dang, A new formulation of curcumin using poly (lactic-co-glycolic acid) - Polyethylene glycol diblock copolymer as carrier material, 2014, vol. 5. M. M. Pérez-Madrigal, L. Cianga, L. J. del Valle, I. Cianga and C. Alemán, Polym. Chem., 2015, 6, 4319-4335. K. Wang, Y. Luo, S. Huang, H. Yang, B. Liu and M. Wang, J. Polym. Sci. Part A Polym. Chem., 2015, 53, 1032-1042. F. Rodríguez-Ropero, J. Casanovas and C. Alemán, J. Comput. Chem., 2008, 29, 69-78. E. Córdova-Mateo, O. Bertran, A. D. Schlüter, M. Kröger and C. Alemán, Soft Matter, 2015, 11, 1116-1126. J. Torras and C. Alemán, J. Phys. Chem. C, 2014, 118, 97699779.

P. T. Bertuoli, A. F. Baldissera, A. J. Zattera, C. A. Ferreira, C. Alemán and E. Armelin, Prog. Org. Coatings, 2019, 128, 4051. T. Stephan, S. A. Muth and M. Schmidt, Macromolecules, 
2002, 35, 9857-9860.

49 I. I. Potemkin, A. R. Khokhlov, S. Prokhorova, S. S. Sheiko, M. Möller, K. L. and Beers and K. Matyjaszewsk, Macromolecules, 2004, 37, 3918-3923.

D. M. Henn, J. A. Holmes, E. W. Kent and B. Zhao, J. Phys. Chem. B, 2018, 122, 7015-7025.

51 L. Rotariu, O. M. Istrate and C. Bala, Sensors Actuators, $B$ Chem., 2014, 191, 491-497.

52 H.-I. Wang, Y.; Chang, in Regenerative Medicine and Tissue Engineering Cells and Biomaterials, ed. D. Eberli, InTech, 2011, pp. 569-588.

53 W. Du, D. Ohayon, C. Combe, L. Mottier, I. P. Maria, R. S. Ashraf, H. Fiumelli, S. Inal and I. McCulloch, Chem. Mater., 2018, 30, 6164-6172.

54 C. Alvim Valente, P. Cesar Chagastelles, N. Fontana Nicoletti, G. Ramos Garcez, B. Sgarioni, F. Herrmann, G. Pesenatto, E. Goldani, M. L. Zanini, M. M. Campos, R. Meurer Papaléo, J. Braga da Silva and N. R. de Souza Basso, J. Biomed. Mater. Res. Part A, 2018, 106, 1522-1534.

55 M. J. Dalby, S. Childs, M. O. Riehle, H. J. H. Johnstone, S. Affrossman and A. S. G. Curtis, Biomaterials, 2003, 24, 927-35.

56 D. Ajami-Henriquez, M. Rodríguez, M. Sabino, R. V. Castillo, A. J. Müller, A. Boschetti-de-Fierro, C. Abetz, V. Abetz and P. Dubois, J. Biomed. Mater. Res. Part A, 2008, 87A, 405417.

57 M. Sun, J. Deng, Z. Tang, J. Wu, D. Li, H. Chen and C. Gao, Colloids Surfaces B Biointerfaces, 2014, 122, 134-142.

58 S. N. S. Alconcel, A. S. Baas and H. D. Maynard, Polym. Chem., 2011, 2, 1442.

59 H.-J. Sung, A. Luk, N. S. Murthy, E. Liu, M. Jois, A. Joy, J. Bushman, P. V. Moghe and J. Kohn, Soft Matter, 2010, 6, 5196. 